\title{
Porosity prediction of calcium phosphate cements based on
}

\section{chemical composition}

\author{
Caroline Öhman ${ }^{\mathrm{a}, \mathrm{b}^{*}}$, Johanna Unosson ${ }^{\mathrm{a}}$, Elin Carlsson ${ }^{\mathrm{a}}$, Maria Pau Ginebra ${ }^{\mathrm{c}}$, \\ Cecilia Persson $^{a}$, Håkan Engqvist ${ }^{a}$
}

${ }^{a}$ Department of Engineering Sciences, Division of Applied Materials Science, The Ångström Laboratory, Uppsala University, Box 534, 75121 Sweden

${ }^{\mathrm{b}}$ Department of Engineering Sciences, Division of Applied Mechanics, The Ångström Laboratory, Uppsala University, Box 534, 75121 Sweden

${ }^{c}$ Biomaterials, Biomechanics and Tissue Engineering Group, Dep. of Materials Science and Metallurgy, Technical University of Catalonia Av. Diagonal 647, 08028 Spain.

\section{*Corresponding author:}

Caroline Öhman

e-mail: Caroline.Ohman@angstrom.uu.se

Telephone: +46 (0)18471 6961

Fax: $+46(0) 184713572$ 


\section{ABSTRACT}

The porosity of calcium phosphate cements has an impact on several important parameters, such as strength, resorbability and bioactivity.

A model to predict porosity for biomedical cements would be a useful tool. At the moment such a model only exists for Portland cements. The aim of this study was to develop and validate a first porosity prediction model for calcium phosphate cements.

On the basis of chemical reaction, molar weight and density of components, a volume-based model was developed and validated using calcium phosphate cement as model material.

$60 \mathrm{~m} \% \beta$-TCP and 40m\% MCPM were mixed with deionized water, at different liquid-topowder ratios. Samples were set for $24 \mathrm{~h}$ at $37^{\circ} \mathrm{C}$ and $100 \%$ relative humidity. Thereafter, samples were dried either under vacuum at room temperature for $24 \mathrm{~h}$ or in air at $37^{\circ} \mathrm{C}$ for 7 days. Porosity and phase composition were determined.

It was found that the two drying protocols led to the formation of brushite and monetite, respectively. The model was found to predict well the experimental values and also data reported in the literature for apatite cements, as deduced from the small absolute average residual errors $(<2.0 \%)$.

In conclusion, a theoretical model for porosity prediction was developed and validated for brushite, monetite and apatite cements. The model gives a good estimate of the final porosity and has the potential to be used as a porosity prediction tool in the biomedical cement field.

Keywords: Calcium phosphate cement, porosity, model, validation 


\section{INTRODUCTION}

Calcium phosphate cements have several beneficial properties for a bone regenerative biomaterial. In addition to being injectable, mouldable and self-setting in vivo, they are bioactive, resorbable and have a composition that is similar to the mineral phase in bone [1].

Calcium phosphate cements are hydraulic, formed by the combination of one or more calcium orthophosphate powders with an aqueous solution. The cement setting reaction is a dissolution and precipitation process, and the entanglement of the precipitated crystals is the mechanism responsible for cement hardening. This process leads to a highly porous structure, consisting of both nano- and microsized pores. The porosity of calcium phosphate cements is a very important factor since it influences the resorbability and is correlated to the surface area, an increase in which favours bioactivity. Furthermore, it is important to have a controlled porosity if the material is to be used as a drug delivery system. However, an increased porosity has a negative effect on the mechanical properties [2], e.g. hardness, compressive strength and diametrial tensile strength [3-6].

In the literature, the influence of numerous factors on the porosity of calcium phosphate cements has been investigated. It has been found that an increase in liquid-to-powder (L/P) ratio increases the porosity of both apatite and brushite cements [3, 5-7]. Espanol et al. (2009) showed that a decrease in medium particle size of the powder reactants did not influence the total porosity of a calcium deficient apatite, although the pore size distribution was affected [5]. It was found by Hofmann et al. (2009) that the particle size distribution of the powder reactants affects the porosity of brushite cement, generally using mainly smaller particles resulted in a lower porosity [3]. Conversely, Engstrand et al. (2014) found that a 
larger average particle size of monocalcium phosphate monohydrate in combination with $\beta$ tricalcium phosphate generally generated a smaller porosity in a brushite cement [7]. Furthermore, it has been found that the addition of hydroxyapatite particles (Hap) as a nucleation agent will influence the porosity. Calafiori et al. (2007) studied calcium phosphate cements based on monocalcium phosphate monohydrate and calcium carbonate mixed with different amounts of Hap and found that specimens containing Hap had a lower porosity after three days [4]. Moreover, the ratio between the, in some cases, two components of the starting powder also modifies the porosity. In the study of Hirayama et al. (2008) it was found that a decrease in the tetracalcium phosphate/dicalcium phosphate anhydrous molar ratio increased the porosity of calcium deficient apatite [6].

Since porosity is an important parameter that conditions the performance of these materials, it would be of significance not only to identify the factors that affect it, but also to establish a model that allows predicting it in a quantitative way. While in the industrial cement area this is common practise, to the authors' knowledge no study has attempted to predict the porosity of calcium phosphate cements. Already in 1948 Powers and Brownyard presented a model for Portland cements, on the porosity of cements as a function of formulation [8]. The theory has thereafter been elaborated by among others Hansen and Brouwers [9-14]. However, these models were all developed for Portland cements, i.e. calcium silicates. In the biomedical field a multitude of cements are used and although calcium silicate is one of them there are still many others, among them calcium phosphate cements, without a validated porosity prediction model. In a recent study [15] a new model for calcium aluminate cements was developed. However, it was based on pre-pressed tablets, which is not applicable for biomedical cements that are aimed to be injected in vivo. 
The aim of the present study was to, on the basis of existing models, develop and validate the first models for porosity prediction of injectable calcium phosphate cements.

\section{MATERIALS AND METHODS}

\section{Theory}

As mentioned before, previous studies [8-14] have provided a good understanding of the hardening process of Portland cement and its effect on porosity.

The liquid to powder ratio, i.e. the amount of water added to the cement powder, will strongly influence the resulting porosity in the cement. At the time of mixing, i.e. before the hydration starts, the cement paste will contain a certain volume of cement powder $\left(v_{c}\right)$ and a certain volume of water $\left(v_{w}\right)$. A volume of filler material $\left(v_{f}\right)$ such as glass, fibres or excess of cement powder might also be present. Hence, the total volume of the paste before hydration is the sum of these volumes, i.e.:

$v_{T o t}=v_{c}+v_{w}+v_{f}$

The lower-case $v$ signifies volumes before hydration.

Upon mixing, the water will dissolve some or all of the cement powder. The amount of powder that will dissolve depends on two factors: 1) the liquid to powder volume ratio in the mixture; and 2) the volume of water needed to dissolve one unit volume of cement powder. This water volume $(x)$ is given by the following schematic chemical reaction:

$x H_{2} O+\sum_{i=1}^{N} y_{i} C_{i} \rightarrow \sum_{j=1}^{M} z_{j} P_{j}$

where $\mathrm{N}$ is the number of different cement powder types $(C)$ in the initial mixture and $M$ is the number of stable reaction products $(P)$ formed by the hydration of these cements. To 
illustrate this, dicalcium phosphate dihydrate (brushite) cement will be used as an example. The chemical reaction when $\beta$-tricalcium phosphate $\left(\beta-\mathrm{Ca}_{3}\left(\mathrm{PO}_{4}\right)_{2}\right.$ and monocalcium phosphate monohydrate $\left(\mathrm{Ca}\left(\mathrm{H}_{2} \mathrm{Po}_{4}\right)_{2} \cdot \mathrm{H}_{2} \mathrm{O}\right)$ form dicalcium phosphate dihydrate $\left(\mathrm{CaHPO}_{4} \cdot 2 \mathrm{H}_{2} \mathrm{O}\right)$, can be written:

$7 \mathrm{H}_{2} \mathrm{O}+\mathrm{\beta}-\mathrm{Ca}_{3}\left(\mathrm{PO}_{4}\right)_{2}+\mathrm{Ca}\left(\mathrm{H}_{2} \mathrm{PO}_{4}\right)_{2} \cdot \mathrm{H}_{2} \mathrm{O} \rightarrow 4 \mathrm{CaHPO}_{4} \cdot 2 \mathrm{H}_{2}$

Hence, 7 moles of water are needed to dissolve $1 \mathrm{~mol}$ of $\beta$-tricalcium phosphate ( $\beta$-TCP) and 1 mol of monocalcium phosphate monohydrate (MCPM), and together they will form 4 mol of dicalcium phosphate dihydrate (DCPD). By using the molar weight and density of the different components, these values can be transformed into volume relations. First by using the molar weight, they can be transformed into a mass relation:

$7 \cdot 18.02 \mathrm{H}_{2} \mathrm{O}+1 \cdot 310.2 \beta-\mathrm{TCP}+1 \cdot 252.2 \mathrm{MCPM}$ $\rightarrow 4 \cdot 172.1 \mathrm{DCPD}$

Thereafter, with the use of the density, the volume relation can be written as following:

$$
\begin{aligned}
& \frac{7 \cdot 18.02}{1.0} \mathrm{H}_{2} \mathrm{O}+\frac{1 \cdot 310.2}{3.14} \beta-T C P+\frac{1 \cdot 252.2}{2.22} \text { MCPM } \\
& \quad \rightarrow \frac{4 \cdot 172.1}{2.33} D C P D
\end{aligned}
$$

If we use one unit volume of cement powder, the volume relation will be:

$$
\begin{aligned}
& 0.594 \mathrm{H}_{2} \mathrm{O}+0.465 \beta-T C P+0.535 \text { MCPM } \\
& \quad \rightarrow 1.393 \text { DCPD }
\end{aligned}
$$

To hydrate one unit volume of cement powder, a certain volume of water is needed (in the example 0.594). This volume of water will be called $k$, and the volume of the hydrates formed (in the example 1.393) will be called $s$.

If a sample consists of one unit volume cement powder $\left(v_{c}=1\right)$ and any volume of water $v_{w}$, the volume of unreacted cement powder left in the sample $\left(V_{c}\right.$, capital letters will be used 
for volumes after the hydration) is given by:

$V_{c}=\left\{\begin{array}{cc}1-\frac{v_{w}}{k} & v_{w}<k \\ 0 & v_{w}>k\end{array}\right.$

The volume of the hydrates formed will depend on the constant $s$ and be given by the expression:

$V_{h}=\left\{\begin{array}{cc}\frac{s}{k} v_{w} & v_{w}<k \\ s & v_{w}>k\end{array}\right.$

The volume of the sample not filled with cement, hydrates or fillers will be empty (or possibly filled with water), i.e. pores. The volume of pores is given by:

$$
V_{p}=1+v_{w}-V_{c}-V_{h}=\left\{\begin{array}{cc}
\left(\frac{1+k-s}{k}\right) v_{w} & v_{w}<k \\
1+v_{w}-s & v_{w}>k
\end{array}\right.
$$

and the volume fraction of pores is:

$$
\Phi_{p}=\frac{1+v_{w}-V_{c}-V_{h}}{1+v_{w}+V_{f}}= \begin{cases}\frac{1+k-s}{1+v_{w}+V_{f}} \cdot \frac{v_{w}}{k} & v_{w}<k \\ \frac{1+v_{w}-s}{1+v_{w}+V_{f}} & v_{w}>k\end{cases}
$$

$V_{f}$ is the volume of filler, i.e. glass, fibres or excess of cement powder added to the cement powder before mixing it with the water. The volume fraction of pores can be correlated to the liquid to cement powder volume ratio $\left(v_{w} / v_{c}\right)$. However, generally porosity is correlated to the liquid to powder (L/P) ratio in $\mathrm{ml} / \mathrm{g}$. The $\mathrm{L} / \mathrm{P}$ ratio is defined as the volume of water $\left(v_{w}\right)$ to the mass of powder, hence by multiplying the volume of cement powder $\left(v_{c}\right)$ by the density of the cement powder the $\mathrm{v}_{\mathrm{w}} / \mathrm{v}_{\mathrm{c}}$ ratio becomes a L/P ratio. In Figure 1 the correlation 
between fractional volume of pores and L/P ratio can be found. According to equation (10), if $\mathrm{v}_{\mathrm{w}}$ of the original cement paste is below the chemical constant $k$, the volume fraction of pores will be kept low (see Figure 1).

In the study of Bultmark et al. calcium aluminate cements were used. In that work it was observed that the hydrates forming during the initial hydration were not dense, perfectly connected crystals but were rather an entanglement of precipitated crystals, which formed a porous matrix. These hydrates will contain an internal porosity $\left(p^{\prime}\right)$ that will be filled with water, which then cannot be used to hydrate the remaining cement. This will affect the values of $k$ and $s$, shifting them to higher values. The previous equations are still valid, but will now have two new parameters $k^{\prime}$ and $s^{\prime}[15]$, which will be given by:

$$
\begin{aligned}
& s^{\prime}=\frac{s}{1-p^{\prime}} \\
& k^{\prime}=k+\frac{s p^{\prime}}{1-p^{\prime}}=k+s^{\prime} p^{\prime}
\end{aligned}
$$

For an arbitrary $\mathrm{p}^{\prime}$ value the optimal L/P will change and shift to a higher value (see Figure 1). However, this might not be the case for all calcium phosphate cements. The pore size distribution will influence the likelihood of water getting trapped inside the crystals, i.e. with larger pores less water will get trapped. Parameters, such as L/P ratio, cement powder average particle size and particle size distribution, will influence the pore size distribution.

Both Powers and Brownyar [8] and Bultmark et al. [15] include a variable called nonevaporable water ( $v_{n}$ and $\pi$, respectively) in their models. The internal porosity $\left(p^{\prime}\right)$ of Portland cement has been determined through different drying techniques, e.g. freezedrying, D-drying, F-drying and ignition [17, 18]. However, regardless of the drying method, the water in some of the internal pores will not evaporate and therefore a certain fraction of 
the internal pores will always contain water. The quantity of water left in the sample will depend on the chosen drying method and is defined as the fraction of non-evaporable water $\left(v_{n}\right.$ or $\left.\pi\right)$. However, in comparison with the porosity added during the mixing of the components and the moulding this fraction will be negligible. Therefore, to simplify this term was omitted in the present model.

\section{Experimental}

To verify the theory, experimental tests were performed. Based on a preliminary study to optimise mechanical properties, a calcium phosphate cement with an initial molar ratio of 60 mol\% $\beta$-TCP and 40 mol\% MCPM was chosen. 20 mol\% of the $\beta$-TCP will not be able to react and will hence be considered as a filler material.

The reactants for the cement were commercially available $\beta$-TCP (CAS 7758-87-4; SigmaAldrich 21218), monocalcium phosphate monohydrate (MCPM) (CAS 7758-23-8, Scharlau CA02110500), and di-sodium dihydrogen pyrophosphate anhydrous (SPP, $\mathrm{H}_{2} \mathrm{Na}_{2} \mathrm{P}_{2} \mathrm{O}_{7}$ ) (CAS 7758-16-9; Fluka 71499). The addition of SPP prolongs the setting time making the cement more suitable for clinical practice [19].

\section{Specimen preparation}

To produce the cements, $\beta$-TCP and MCPM with $1 \mathrm{wt} \%$ SPP at the ratio $60 \mathrm{~m} \% \beta$-TCP and 40 m\% MCPM (1.924 g $\beta$-TCP per 1.000 g MCPM) were hand-mixed with deionized water (mixing time $30 \mathrm{~s}$ ) on mixing paper using a metal spatula, at liquid-to-powder (L/P) ratios of $0.4,0.5,0.6$ or $0.7 \mathrm{ml} / \mathrm{g}$. Preliminary tests were done to verify the range of $\mathrm{L} / \mathrm{P}$ that could be used and it was found that at a L/P of 0.3 it was impossible to obtain a homogenous paste and at a L/P of 0.8 the cement paste was too liquid to be moulded. The cement slurries were cast without compaction into moulds to produce cylindrical samples $(6 \mathrm{~mm}$ diameter, $12 \mathrm{~mm}$ 
height). Samples were allowed to set for 24 hours at $37{ }^{\circ} \mathrm{C}$ and $100 \%$ relative humidity. After setting, wet weight $\left(\mathrm{m}_{\text {wet }}\right)$ and apparent volume $\left(\mathrm{V}_{\mathrm{app}}\right)$ of the samples was determined by measuring the dimensions of the specimens with a calliper. It has been shown that a water poor environment will promote monetite formation rather than brushite [16, 20]. Therefore, two different protocols of drying were used to obtain two different phase compositions of the hardened cement, giving two sets of data for the model validation. A first set of samples (10 samples for each L/P) were dried in vacuum at room temperature (RT, $21^{\circ} \mathrm{C}$ ) for 24 hours (RT group), while the second set of specimens (20 samples for each L/P) were dried in open containers at $37^{\circ} \mathrm{C}$ for 7 days $\left(37^{\circ} \mathrm{C}\right.$ group). Thereafter, the dry weight $\left(m_{\text {dry }}\right)$ of each specimen was determined.

\section{Porosity measurements}

Two different methods to measure the porosity of the samples were used.

Methanol submersion

The approximate porosity of the different cement compositions was evaluated by submerging the dried samples in $10 \mathrm{ml}$ methanol for two days and then recording the weights of the samples with methanol inside the pores $\left(\mathrm{m}_{\mathrm{MeOH}}\right)$. The porosities of the material $\left(\mathrm{P}_{\mathrm{MeOH}}\right)$ could then be calculated [16]:

$$
P_{\mathrm{MeOH}}=\frac{m_{\mathrm{MeOH}}-m_{d r y}}{\rho_{\mathrm{MeOH}} V_{a p p}}
$$

\section{Helium pycnometry}

The skeletal density ( $\left.\rho_{\text {skeletal }}\right)$ of the dried samples was determined by helium pycnometry (Accupyc 1330, Micromeritics). The average skeletal densities were calculated based on 10 measurements. The porosity $\left(\mathrm{P}_{\mathrm{pyc}}\right)$ of each sample could then be calculated as: 
$P_{p y c}=1-\frac{m_{\text {dry }}}{\rho_{\text {skeletal }} V_{a p p}}$

\section{$X$-ray diffraction (XRD) analysis}

To verify the phase composition of the two different drying protocols, samples with L/P of 0.4 and $0.7 \mathrm{ml} / \mathrm{g}$ were analysed with XRD. The samples were analysed before (wet group) and after drying for the two different drying groups (RT group and $37^{\circ} \mathrm{C}$ group). The samples were thoroughly ground using a mortal until a fine powder was obtained. The analysis was performed using a D8 Advanced (Bruker) in a theta-theta setup with Cu-ka irradiation and

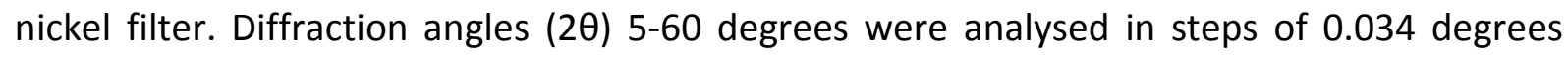
with 0.75 second per step and a rotation speed of $80 \mathrm{rpm}$. Rietveld refinement with BGMN software (BGMN, Germany) was used to calculate the phase compositions, with the reported result being the mean of three measurements with the relative error as $2.77 \mathrm{x}$ standard deviation according to ASTM E177-13 [21]. The structures used for the refinement were; monetite from PDF \#04-009-3755 [22], brushite from PDF \# 04-013-3344 [23], $\beta$-TCP from PDF \# 04-008-8714 [24], and $\beta$-calcium pyrophosphate ( $\beta$-CPP) from PDF \# 04-009-3876 [25].

\section{Model validation with literature data}

To extend the model validation to include more than just one initial composition, porosity data from the literature was used for a calcium deficient apatite made at different L/P ratios [5]. The hydrolysis reaction for this type of cement is:

$\mathrm{H}_{2} \mathrm{O}+3 \alpha-\mathrm{Ca}_{3}\left(\mathrm{PO}_{4}\right)_{2} \rightarrow \mathrm{Ca}_{9}\left(\mathrm{HPO}_{4}\right)\left(\mathrm{PO}_{4}\right)_{5}(\mathrm{OH})$

By using equation (16) together with equations (4-6) $k, s, k^{\prime}$ and $s^{\prime}$ values can be calculated.

The models (including or excluding $\mathrm{p}^{\prime}$ ) were thereafter compared to the reported porosity 
values.

\section{Statistical analysis}

A one-way analysis of variance (ANOVA) was used to analyse the effect of L/P ratio, drying method and porosity measurement technique on the cement porosity. Since Levene's test did not confirm homogeneity of variances, Tamhane's post hoc test was used to evaluate differences between L/P ratios. A one-way ANOVA was also used to determine the effect of L/P ratio and drying method on the phase composition, with each phase type being analysed separately. Absolute average residual error was calculated for the models (both excluding and including possible internal porosity $\left.\left(p^{\prime}\right)\right)$. A significance level of $\alpha=0.05$ was used for all tests.

\section{RESULTS}

The results from the porosity measurements can be found in Table 1 . As expected it was found that the L/P ratio had a significant effect on the porosity ( $p<0.001$ for all comparisons). Furthermore, the drying technique was found to have a significant effect on the porosity ( $p<0.001$ for all comparisons). The measuring technique did not significantly influence the porosity values in the RT group ( $p>0.37$ for all comparisons). Conversely, the measurement technique was found to have a significant influence in the $37^{\circ} \mathrm{C}$ group $(p<0.01$ for all comparisons).

The results from the XRD analysis can be found in Figure 2. It was found that the amounts of brushite and monetite were not different for the wet and room temperature dried specimens ( $p=0.11$ and $p=0.39$, respectively). Conversely, the specimens dried at $37^{\circ} \mathrm{C}$ were found to have a significantly higher amount of monetite and a lower amount of brushite 
than the other two $(p<0.001)$.

Furthermore, it was found that the $0.4 \mathrm{ml} / \mathrm{g}$ specimens had a higher amount of monetite and a lower amount of brushite than the $0.7 \mathrm{ml} / \mathrm{g}$ specimens when dried at $37^{\circ} \mathrm{C}(\mathrm{p}<0.002$ for both).

Based on the XRD analysis that demonstrated two different phase compositions for the specimens dried under vacuum at room temperature for $24 \mathrm{~h}$ and the ones dried at $37^{\circ} \mathrm{C}$ for 7 days, two separate models were developed. The results for the two L/P ratios were pooled. The first model for the RT group was based on the example from the Theory section since mainly brushite was found, the only difference being the addition of $20 \mathrm{~m} \%$ of $\beta$-TCP as filler. The $k$ and $s$ values were therefore the same as previously, 0.594 and 1.397, respectively. To investigate whether an internal porosity ( $\left.p^{\prime}\right)$ needed to be included in the model or not, the experimental values were compared to calculated values from the model including $p^{\prime}$, using different $p^{\prime}$ values (using $p^{\prime}$ for Portland cements $\left(p^{\prime}=0.28\right)[7]$ as a starting point). In the case of brushite, not including $\mathrm{p}^{\prime}$ gave the lowest absolute average error $(1.5 \%$ $\pm 0.4 \%)$. In fact, the absolute average error increased with an increasing $p^{\prime}\left(p^{\prime}=0.08: 5.5 \% \pm\right.$ $0.9 \%, p^{\prime}=0.18: 11.6 \% \pm 1.6 \%$ and $\left.p^{\prime}=0.28: 19.4 \% \pm 2.6 \%\right)$. In Figure 3 the models (without and with example $p^{\prime}$ values $(0.08,0.18$ and 0.28$\left.)\right)$ and the pooled experimental results of porosity are compared.

XRD analysis confirmed that the specimens dried at $37^{\circ} \mathrm{C}$ had undergone a phase transformation. Rather than consisting mainly of brushite, a large proportion of monetite was found. Excluding the filler material (i.e. excess of $\beta$-TCP) and the small amounts of $\beta$ $\mathrm{CPP}$, the following chemical reaction had hence taken place: 
$1.24 \mathrm{H}_{2} \mathrm{O}+\beta-\mathrm{Ca}_{3}\left(\mathrm{PO}_{4}\right)_{2}+\mathrm{Ca}\left(\mathrm{H}_{2} \mathrm{PO}_{4}\right)_{2} \cdot \mathrm{H}_{2} \mathrm{O} \rightarrow 1.12 \mathrm{CaHPO}_{4} \cdot 2 \mathrm{H}_{2} \mathrm{O}+2.88 \mathrm{CaHPO}_{4}$

Applying this reaction to equations (4-6) a $k$ value of 0.105 and an $s$ value of 1.020 were found. Again, different $p^{\prime}$ values were tested to verify the need to include an internal porosity in the model. It was found that also for the monetite cement the model without $p^{\prime}$ gave the lowest absolute average error $(2.0 \% \pm 0.6 \%)$. In this case as well the average error increased with an increasing $p^{\prime}$ (i.e. $p^{\prime}=0.08: 4.5 \% \pm 0.8 \%, p^{\prime}=0.18: 9.0 \% \pm 1.4 \%$ and $p^{\prime}=0.28$ : $14,7 \% \pm 2.1 \%)$. A model based on these values and the experimental values can be seen in Figure 4.

For the apatitic cement [5], $k$ and $s$ were calculated to be, 0.061 and 1.013 , respectively. As previously different values of internal porosity $\left(p^{\prime}\right)$ were tested. Conversely to the brushite and monetite results, it was found that for apatite a $p^{\prime}$ value of 0.27 gave the lowest absolute average error values $(0.3 \% \pm 0.3 \%)$, in comparison with the model excluding $\mathrm{p}^{\prime}$ $(14.6 \% \pm 1.8 \%)$ and for example $p^{\prime}$ values of $0.08(11.1 \% \pm 1.4 \%), 0.18(5.8 \% \pm 0.6 \%)$ and $0.28(1,0 \% \pm 0.4 \%)$. Using a $p^{\prime}$ of $0.27, k^{\prime}$ was calculated to be 0.435 and $s^{\prime} 1.388$. In Figure 5 the models and the data reported in the literature are compared.

\section{DISCUSSION}

The aim of this study was to create a model to predict the porosity of injectable calcium phosphate cements. On the basis of chemical reaction, molar weight and density of components, a volume based model was developed. The model was verified experimentally with a calcium phosphate cement and also through comparison with literature data [5]. Two drying protocols were used, which led to different phase compositions (i.e brushite cement and monetite/brushite cement). The model was found to predict well the experimental 
values, as deduced from the small absolute residual errors, $1.2 \%, 1.6 \%$ and $0.3 \%$ for brushite, monetite and apatite, respectively. To the authors' knowledge, no other study has tried to predict the porosity of calcium phosphate cements, making a direct comparison difficult. Nevertheless, the present work is in line with previous studies on porosity predictions of other types of cements, e.g. Portland [8] and calcium aluminate cements [15]. In fact, the present model is based on those models. However, in previous studies a factor called "non-evaporable water" was included. This term was omitted in the present study since it was believed to be negligible in comparison to the effect of the porosity introduced during the preparation of the specimens (e.g. mixing, moulding). Furthermore, Bultmark et al. [15] introduced a term for the possible internal porosity $\left(p^{\prime}\right)$ of the cement. The internal porosity is expected to entrap water that cannot be used for hydration of the remaining cement, leading to higher values of $k$ and $s$. This term was included in the present study as well; however, it was observed that the incorporation of this parameter resulted in a worse prediction of the porosity in two out of three cases (higher absolute average error values for brushite and monetite). This indicates that, opposite to the calcium aluminate cements, at least in this case the porosity of brushite and monetite cements was not completely closed and hence water was not being entrapped between the crystals to the same extent. Nevertheless, a term for the porosity induced during specimen preparation (i.e. mixing and moulding) was not included in the model. This porosity might have had a counteractive effect and it cannot be ruled out that it might have concealed the need to include $p^{\prime}$ in the models for brushite and monetite. On the other hand it was noted that although a term for porosity introduced during specimen preparation was excluded in the apatite model as well, $\mathrm{p}^{\prime}$ was needed to predict correctly the porosity of the apatite cements. Absolute average residual errors decreased from $14.6 \%$ to $0.3 \%$ when including a $p^{\prime}$ of 0.27 . The apatite 
cement from the literature [5] has been found to have smaller pores in comparison with a brushite cement with similar composition to the one used in the present study [16]. Therefore, it is more likely that this type of cement will have porosities that are completely closed where some of the water might get entrapped. In this study the $p^{\prime}$ value was derived from the model and not determined experimentally. This might have influenced the outcome and it should be determined to obtain a full validation of the model for apatite cement. Nevertheless, the model predicted well the porosity, indicating that the $p^{\prime}$ value is approximately 0.27 .

In addition to the porosity that might be introduced during cement preparation (e.g. mixing and moulding) other factors, such as particle size distribution of the cement powder, have been found to influence the porosity $[3,5,7]$. To simplify the model both these factors were omitted. Adding more factors to the model would have made it more complicated and would have required a considerably larger number of experiments. However, including them would probably have improved the accuracy of the model. Further studies are needed to estimate the influence they would have had on the predictions. On the other hand, even without these factors the model gave a simple but still good estimate of the porosity.

In the present study, two different drying protocols were used. This resulted in two sets of specimens with different phase compositions. XRD Rietveld refinement analysis demonstrated that drying at $37^{\circ} \mathrm{C}$ for seven days causes a phase transformation from almost pure brushite cement to a cement containing large amounts of monetite. This is in agreement with previous studies $[16,20]$ where it has been shown that a water poor environment, e.g. premixed cements, will promote monetite cement instead of brushite cement. A limit of the present study is that the phase quantities were pooled, even though it 
was found that the lower L/P ratio $(0.4 \mathrm{~g} / \mathrm{ml})$ had a higher amount of monetite than the higher L/P ratio $(0.7 \mathrm{~g} / \mathrm{ml}), 55.1 \%$ and $45.4 \%$, respectively. Nevertheless, taking the difference in phase composition into account would have made it difficult to determine $k$ and $s$ for the model. Since the Rietveld refinement has an accuracy of about $2 \%$ and in addition does not measure amorphous phases (although most parts of brushite/monetite cements are crystalline) and the model correlated very well to the experimental values, it was deemed that the effect of the phase composition difference was negligible.

In the present study two different porosity measurement techniques were used, i.e. helium pycnometry and methanol submersion. In the set of specimens dried at room temperature no difference between the two techniques were found. Conversely, in the second set of specimens $\left(37^{\circ} \mathrm{C}\right.$ group) a difference in porosity was found between the two techniques. This difference might be due to that during drying brushite will transform to monetite, through elimination of the water bound to the crystal. This will create pores at the molecular level and it could be that the larger methanol molecules, in comparison to the helium molecules, cannot enter these cavities, leading to an apparent lower porosity. However, further studies are needed to verify this statement. Furthermore, during the phase transformation from brushite to monetite, a small decrease in the apparent volume could occur. As the apparent volume was measured on the samples before drying, this might affect the porosity results. If a decrease occurred helium pycnometry would overestimate the porosity, while methanol submersion would underestimate the porosity [16], another possible explanation to the significant difference for the $37^{\circ} \mathrm{C}$ group.

A second limitation to this study is that only two formulations of the initial components of the cement were used. Nevertheless, the different drying protocols resulted in brushite and 
monetite and the model was able to predict accurately the porosity of all three outcomes, including the apatite data from the literature. This indicates that the model is versatile and should work for other types of brushite, monetite and apatite cements. Another concern might be the relatively low specimen number (10 samples for each L/P ratio). However, the coefficient of variance was generally less than $2 \%$, except for one case where it was $8 \%$. Since the intraspecimen variation is expected to be around that number the sample size was considered sufficient.

In conclusion, a theoretical model for porosity prediction of calcium phosphate cements was developed and validated. The results are promising and the model can be used to predict porosity of brushite, monetite and apatite cements based on their chemical composition.

\section{Acknowledgments}

This work was partially supported by Stiftelsen Lars Hiertas minne (FO2011-0445), the Swedish Foundation for International Cooperation in Research and Higher Education (STINT, GA IG2011-2047), FP7 NMP project Biodesign (GA 262948), the Swedish Research Council (VR, project number 621-2011-6258 and project number 2011-3399) and the Swedish Institute (SI, 00845/2011).

\section{Disclosures}

The authors declare that there are no conflicts of interest.

\section{REFERENCES}

[1] Bohner M. Physical and chemical aspects of calcium phosphates used in spinal surgery. Eur Spine J. 2001;10 Suppl 2:S114-21.

[2] Matusinović T, Šipušić J, Vrbos N. Porosity-strength relation in calcium aluminate 
cement pastes. Cement Concr Res. 2003;33:1801-6.

[3] Hofmann MP, Mohammed AR, Perrie Y, Gbureck U, Barralet JE. High-strength resorbable brushite bone cement with controlled drug-releasing capabilities. Acta biomater. 2009;5:43-9.

[4] Calafiori AR, Di Marco G, Martino G, Marotta M. Preparation and characterization of calcium phosphate biomaterials. J Mater Sci Mater Med. 2007;18:2331-8.

[5] Espanol M, Perez RA, Montufar EB, Marichal C, Sacco A, Ginebra MP. Intrinsic porosity of calcium phosphate cements and its significance for drug delivery and tissue engineering applications. Acta biomater. 2009;5:2752-62.

[6] Hirayama S, Takagi S, Markovic M, Chow LC. Properties of Calcium Phosphate Cements With Different Tetracalcium Phosphate and Dicalcium Phosphate Anhydrous Molar Ratios. J Res Natl Inst Stand Technol. 2008;113:311-20.

[7] Engstrand J, Persson C, Engqvist H. The effect of composition on mechanical properties of brushite cements. J Mech Behav Biomed Mater. 2014;29:81-90.

[8] Powers TC, Brownyard TL. Studies of the physical properties of hardened cement paste. Research Laboratories of the Portland Cement Association, Chicago 1948;Bulletin 22.

[9] Brouwers HJH. The work of Powers and Brownyard revisited Part 1. Cem Concr Res 2004;34:1697-716.

[10] Brouwers HJH. The work of Powers and Brownyard revisited: Part 2. Cem Concr Res 2005;35:1922-36.

[11] Hansen TC. Physical structure of hardened cement paste: a classical approach. Mat Struct 1986;19:423-36.

[12] Jensen OM, Hansen PF. Water-entrained cement-based materials: I. Principles and theoretical background. Cem Concr Res 2001;31:647-54.

[13] Taylor HFW. Cement chemistry. 2nd ed. London, UK; 1997. 
[14] Neville AM. Properties of Concrete. 4th ed. Harlow, UK; 2000.

[15] Bultmark F, Lööf J, Öhman C, Harmansson L, Engqvist H. Theoretical model to predict porosity and mechanical strenth of low w/c calcium-aluminate cements. Submitted.

[16] Engstrand Unosson J, Persson C, Engqvist H. An evaluation of methods to determine the porosity of calcium phosphate cements. J Biomed Mater Res B Appl Biomater. 2014; doi: 10.1002/jbm.b.33173.

[17] Korpa A, Trettin R. The influence of different drying methods on cement paste microstructures as reflected by gas adsorption: Comparison between freeze-drying (F-drying), D-drying, P-drying and oven-drying methods. Cem Concr Res 2006;36:634-49.

[18] Coperland LE, Hayes JC. The determination of non-evaporable water in hardened Portland cement paste. Research and Development Laboratories of the Portland Cement Association 1953;Bulletin 47.

[19] Bohner M, Lemaitre J, Ring TA. Effects of sulfate, pyrophosphate, and citrate ions on the physicochemical properties of cements made of beta-tricalcium phosphate-phosphoric acid-water mixtures. J Am Ceram Soc 1996;79:1427-34.

[20] Gbureck U, Dembski S, Thull R, Barralet JE. Factors influencing calcium phosphate cement shelf-life. Biomaterials. 2005;26:3691-7.

[21] ASTM. Standard Practice for Use of the Terms Precision and Bias in ASTM Test Methods.

[22] Dickens B, Bowen JS, Brown WE. A Refinement of the Crystal Structure of CaHPO4 (Synthetie Monetite). Acta Crystallogr, Sect B: Struct Sci. 1971:797-806.

[23] Curry NA, Jones DW. Crystal structure of brushite, calcium hydrogen orthophosphate dihydrate: a neutron-diffraction investigation. J Chem Soc A 1971:3725-9.

[24] Dickens B, Schroeder LW, Brown WE. Crystallographic studies of the role of Mg as a stabilizing impurity in $\beta$-Ca3(PO4)2. The crystal structure of pure $\beta$-Ca3(PO4)2. J Solid State 
Chem 1974;10:232-48.

[25] Boudin S, Grandin A, Borel MM, Leclaire A, Raveau B. Redetermination of the BetaCa2P2O7 Structure. Acta Crystallogr, Sect C: Cryst Struct Commun 1993;C49:2062-4. 


\section{Figure captions}

Figure 1 - Porosity prediction for different L/P. The solid line indicating the original model and the dashed line the model including $p^{\prime}$ ( $p$ ' was assumed to be $28 \%$, experimentally determined by and Brownyar for Portland cements [8]). The vertical dashed lines indicate the $L / P$ values corresponding to $k$ and $k^{\prime}$.

Figure 2 - Phase composition (average \pm relative error) at $0.4 \mathrm{ml} / \mathrm{g}$ and $0.7 \mathrm{ml} / \mathrm{g}$ for wet samples (wet) and for samples dried according to the two different drying methods (in vacuum at $\mathrm{RT}$ for $24 \mathrm{~h}(\mathrm{RT})$ and at $37^{\circ} \mathrm{C}$ for 7 days $\left(37^{\circ} \mathrm{C}\right)$ ).

Figure 3 - The experimental results (RT group) plotted against the theoretical model for brushite (including the excess powder as filler in the model), with or without including internal porosity $\left(p^{\prime}\right)$. Examples values of $p^{\prime}$ are represented $(0.08,0.18$ and 0.28$)$. For Portland cements, $p^{\prime}$ has experimentally been determined to be 0.28 [8]).

Figure 4 - The experimental result $\left(37^{\circ} \mathrm{C}\right.$ group) plotted against the model (including the excess powder as filler) for an outcome of $72 \%$ monetite and $28 \%$ brushite, with or without including internal porosity $\left(p^{\prime}\right)$. Examples values of $p^{\prime}$ are represented $(0.08,0.18$ and 0.28$)$. For Portland cements, $p^{\prime}$ has experimentally been determined to be 0.28 [8]).

Figure 5 - The results reported in the literature [5] plotted against the model for apatite, with or without including internal porosity $\left(p^{\prime}\right)$. Examples values of $p^{\prime}$ are represented $(0.08$, 0.18 and 0.27 ).

Table 1 - Porosity of the two different groups measured with the two different techniques (average $\pm \mathrm{SD}$ ). 
Figure 1

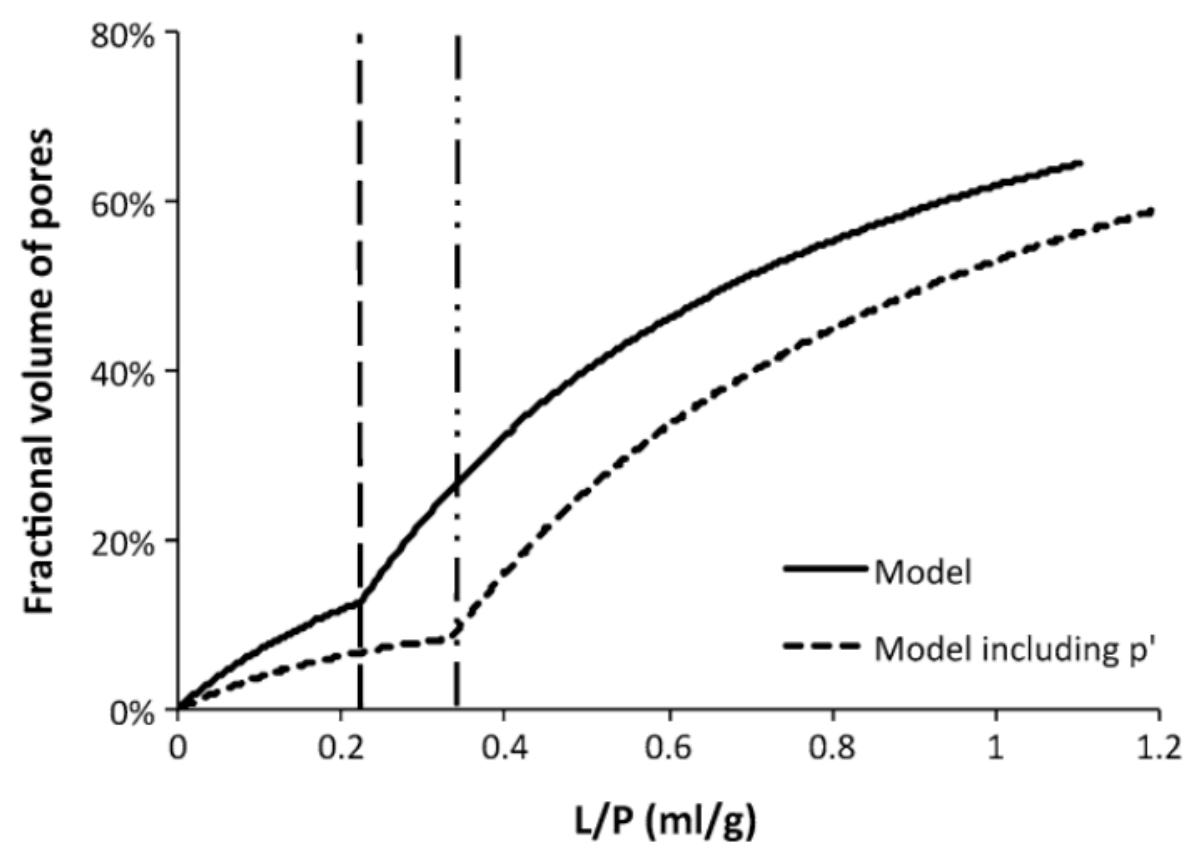


Figure 2

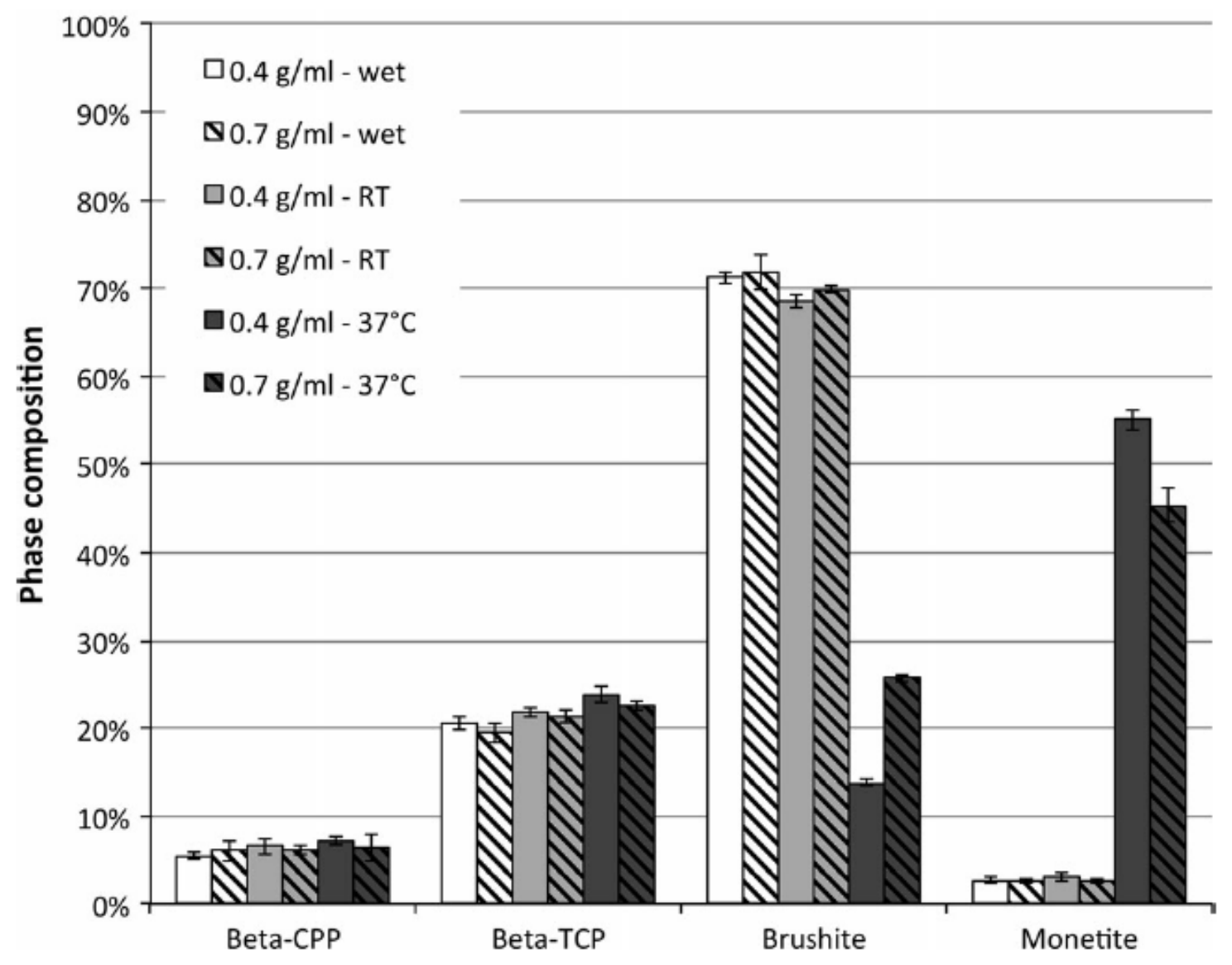


Figure 3

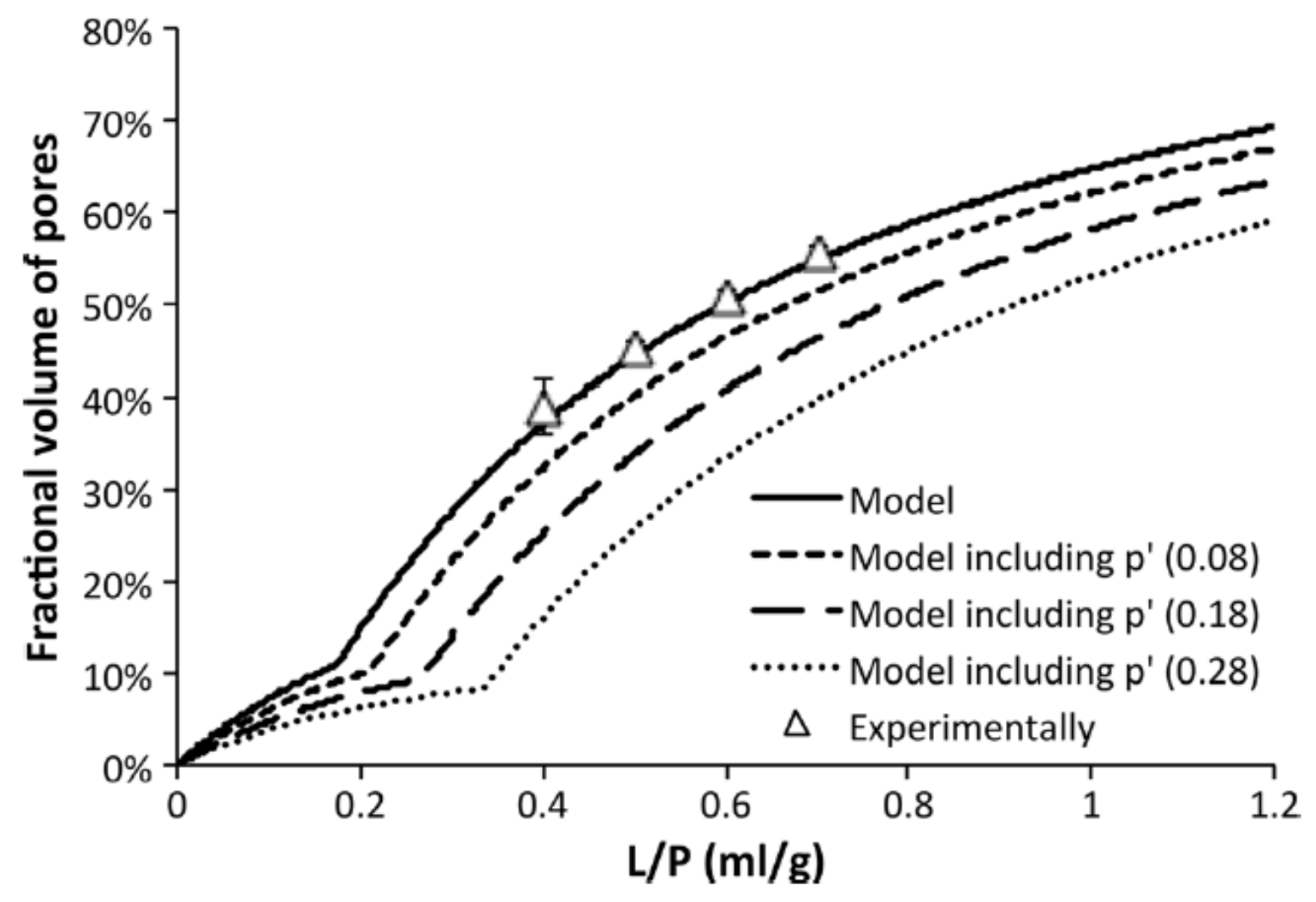


Figure 4

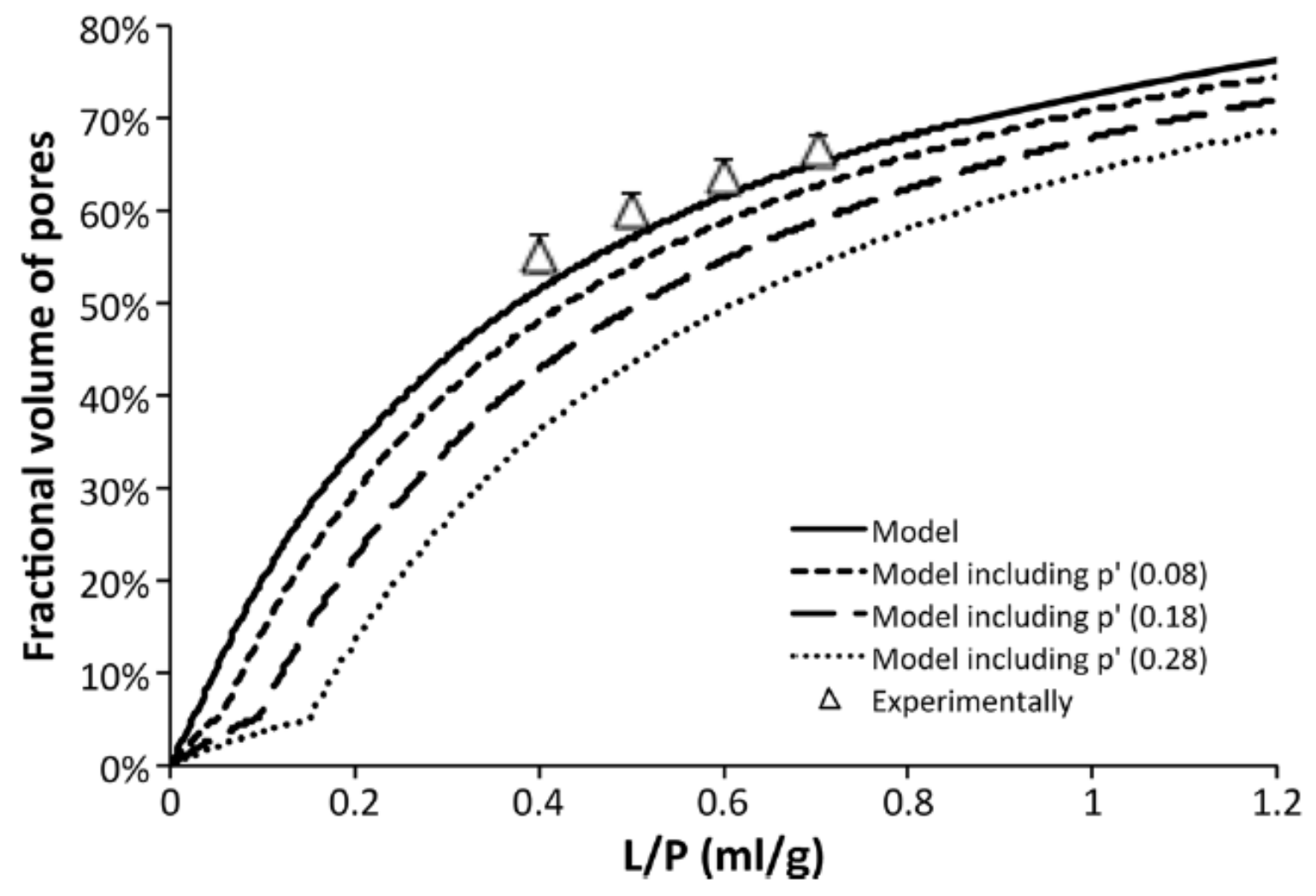


Figure 5

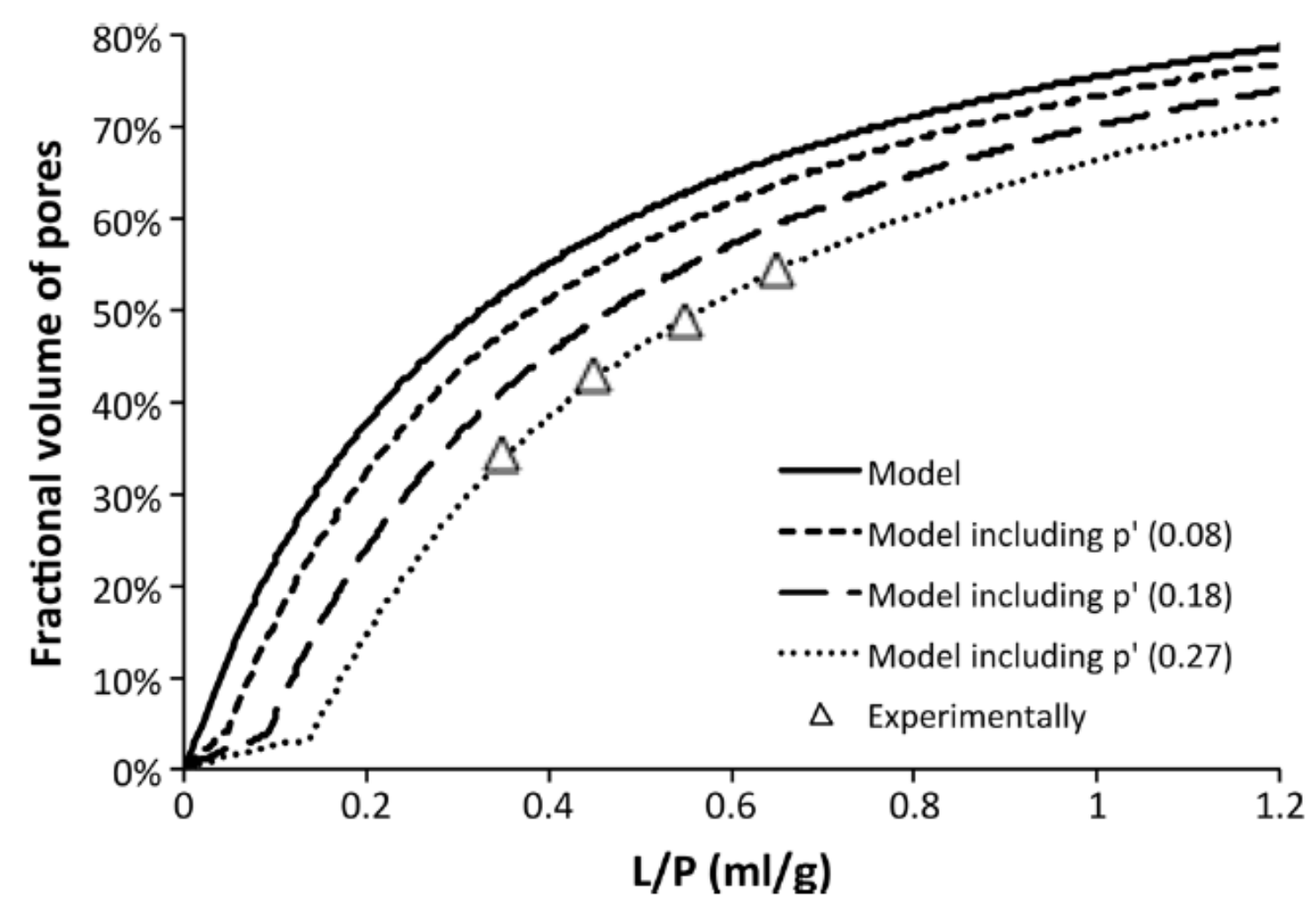

Fig. 5 The results reported in the literature [5] plotted against the model for apatite, with or without including internal porosity $\left(p^{\prime}\right)$. Examples values of $p^{\prime}$ are represented $(0.08,0.18$ and 0.27$)$ 
Table 1

\begin{tabular}{|c|c|c|c|c|}
\hline \multirow[t]{3}{*}{$\mathrm{L} / \mathrm{P}(\mathrm{ml} / \mathrm{g})$} & \multicolumn{4}{|l|}{ Porosity (\%) } \\
\hline & \multicolumn{2}{|l|}{ RT group } & \multicolumn{2}{|l|}{$37^{\circ} \mathrm{C}$ group } \\
\hline & Pycnometry & Methanol & Pycnometry & Methanol \\
\hline 0.4 & $39.3( \pm 0.4)$ & $38.8( \pm 3.5)$ & $57.8( \pm 1.4)$ & $53.9( \pm 0.7)$ \\
\hline 0.5 & $45.6( \pm 0.1)$ & $45.0( \pm 0.8)$ & $61.9( \pm 0.9)$ & $58.9( \pm 0.7)$ \\
\hline 0.6 & $51.5( \pm 0.1)$ & $50.4( \pm 0.8)$ & $66.1( \pm 1.0)$ & $62.8( \pm 0.6)$ \\
\hline 0.7 & $56.1( \pm 0.2)$ & $55.3( \pm 1.0)$ & $68.6( \pm 0.5)$ & $66.0( \pm 0.7)$ \\
\hline
\end{tabular}

